\title{
Types of Family Adopting Orphaned Learners - A Reflection on Challenges and Coping Strategies of Orphaned Learners in Public Primary Schools in Kenya.
}

\author{
Alice A. Owino \\ Sugar Research Primary School, Kisumu \\ Violet Kafwa Nabwire \\ Department of Curriculum Instruction \\ Educational Media, Moi University - Kenya
}

\begin{abstract}
Orphan hood is a depressing status in life and has adverse effects yet every child in Kenya has a right to quality education that should lead to good learning in pursuance to Universal Primary Education (UPE). Majority of orphaned learners are widely affected and fail to attain good performance. However exceptional few perform well and attain high grades enabling them to join good High schools and pursue their academic dreams. The study therefore assessed the types of family set up that host orphaned learners and the coping strategies they device in the new set up. Descriptive survey design was used to collect data from 13 public primary schools with a sample constituting of head teachers, teachers, and orphaned learners. Random sampling technique was used to select the schools; purposive sampling technique choice head teachers and orphaned learners, and random sampling selected teachers. A questionnaire, interview schedule, and document analysis collected the qualitative and quantitative data. Descriptive statistics analyzed the quantitative data and findings were presented in the frequency/mean tables and graphs while qualitative data was presented thematically. The study established that a good number of orphaned learners in Kenya lived with older siblings and received a lot of motivation and encouragement from the sibling that led to their achievement. The second highest number of orphaned learners lived with grandparents who were economically unable to manage the responsibility. The study concluded that majority of orphaned learners lacked guidance from adults and therefore recommended that grandparents who took care of the orphans but not fully financially assisted by the government should be supported, and the Ministry of Health in collaboration with other good will stake holders to launch health and nutrition program in schools where none exists. The findings of the study are important to the government, educational planners, stakeholders, parents and the community.
\end{abstract}

Key Words: Family Set Up, Academic Achievement, Orphaned Learners, Primary Schools, Kenya

\section{INTRODUCTION}

Current reports indicate that there are between 143 million and 210 million orphans worldwide [1] and every day 5,760 more children become orphans. This renders many children orphaned and 2,102,400 more children become orphans every year in Africa alone. $92 \%$ of the world's orphans are in developing countries. The increasing situation of orphan hood is incapacitating children's learning ability.

It is estimated that by the year 2020 with the rate that children are becoming orphaned, there will be more than 200 million children orphaned around the globe and this is over $2.8 \%$ of the 
world's population [2]. In Russia and Ukraine, studies have shown that $10 \%-15 \%$ of these children commit suicide before they reach age eighteen yet single child is precious child just like other children whose parents are alive. The negative effects of orphan hood have important implications for future opportunities in terms of education, employment, health, social support and economic development. [3] Find that parental loss decreases school attendance and participation rates of children by seven percentage points. Orphans are at risk and significantly affected by their inability to meet basic needs such as shelter, food, clothing health care and education [4]. There are more orphans in sub-Saharan Africa than all of the children in Denmark, Ireland, Norway, Canada, Sweden combined. This calls for interventions and ways of caring for the orphans in sub-Saharan Africa.

About 150 million boys and girls which is $8 \%$ of the child population in developing countries, have lost at least one of their parents [5]. Above all in sub-Saharan Africa, the high rates of orphan hood can be largely attributed to diseases, accidents and natural disasters. The Research Council [6] stated that Durban, South Africa will face the challenge by 2015 of having to look after 1.85 million children orphaned by HIV/ AIDS pandemic.

There are over 2.8 million orphans in Uganda [7]. Out of this, half of the population is under the age of 15 years old. There are suspected over 10.6 million cases of malaria deaths leaving behind millions of orphans. This has forced many children to resort to be in Ugandan streets where they can beg and get something to eat. A recent survey estimates that every fourth family in Uganda is hosting an orphan. 57\% of the total populations in Uganda are children of whom $15 \%$ are orphans with $46 \%$ of the orphans due to HIV/AIDS. The orphans are living with caregivers either too old or too young and most often impoverished to provide adequately for their needs such as physiological, emotional and spiritual needs although a good number of orphans are in schools [8]. The burden of caring orphans is thus putting too heavy strain to the extended family.

Data collected by UNICEF on over 10,000 children in Burundi showed that a significantly lower percentage of children with both parents deceased are in school compared with children with both parents alive [9]. Thus at the national level, the orphans crisis poses a challenge to preserve Africa's human capital asset for the future. The impact of the orphans' crisis in the countries is being felt on households and communities and due to the sheer numbers involved; it is also being felt as a systematic shock on economy. This means that if no action is taken to help the orphaned children then Africa is likely to have economy wide impact.

In Kenya the situation is equally the same. Most orphans in Kenya and indeed the highest percentage is as a result of parents dying from the dreaded disease HIV/AIDS. The total number of pupils in Kisumu East District is 21,352 out of which $30 \%$ of the total populations are orphaned children. This gives a total of 6,406 orphaned children of which $55 \%$ are girls $(3,523)$ and the remaining $45 \%$ are boys $(2,883)$. A research study by Inter-Religious Council of Kenya sponsored by [10] indicated that most orphaned children were not able to access education due to various barriers and hindrances. Such barriers include lack of proper school uniform, inadequate food, non payments of the hidden costs like activity and exam money even though there is free education. Although the government of Kenya provides instructional materials (IM) to all primary schools to support free education, there is still inadequate support received by orphaned learners which constrain their effective learning. However there are exceptional cases where orphans who are either adopted or not performed excellently well. 


\section{Statement of the Problem}

The existing number of orphans in Kenya today is alarming and has continued to escalate in the whole country. Accordingly orphans are being absorbed in families already constrained with poverty, large family sizes, social disintegration, loss of productive members and ill health due to HIV infection and age induced chronic conditions [11]. Given the situation it is necessary to note that these orphans are part of the population of the country and so are important as any other citizen. Government statistics reveal that the number of orphaned learners has risen from $20 \%$ of the total population of the children in Kisumu East District to $30 \%$. This is from 4,270 to 6,406 orphaned learners in Primary Schools. [12]. Orphaned learners are substantially more likely to drop out of school than non-orphans. The changes in family circumstances to some extent deprive these orphaned learners of the stimulus resources found in the normal family

Due to this adverse situation, orphaned children schooling outcomes is significantly worse than those of non-orphaned children. Orphans are at risk and significantly affected by their inability to meet and access basic needs such as food, clothing, and health care among others [13]. However, there are exceptional cases where orphaned learners perform well and excel in their academics despite the challenges they go through leaving one to wonder and question the causes and contributors to their achievement and good performance. It is interesting that Winam Division outperforms Kadibo Division in KCPE yearly with 2352 orphans yearly yet Winam has a larger number of orphaned learners of 4054. In the year 2009, 2010 and 2012 Winam Division had mean scores of 267, 262 and 278 respectively while Kadibo Division had 203, 213 and 220 respectively in KCPE [14].

The scenario therefore calls for some empirical data to explain the situation in terms of: types of family set up the orphaned learners are adopted into after parental death? Whether there are challenges orphaned learners face in effort to fit into these new family set ups that probably trigger their efforts to work hard and perform better? Studies which have been conducted on the type of family set up where orphaned learners live in, target all orphans especially those orphaned as a result of AIDS pandemic, however there is a gap when it comes to their survival mechanisms in such family set up that may impact on their academic achievement. Hence it is in this context that the researchers feel the need to assess and find out the type of family set up orphaned learners live with and its' influence on their academic achievement in Winam Division, Kisumu County.

\section{Objectives of the Study}

The study examined the following objectives:

a. To establish the type of guardian of adopted orphaned learners of public primary schools in Winam division of Kisumu County, Kenya

b. To assess the support received from the new family adopted orphaned learners of public primary schools in Winam division of Kisumu County, Kenya

c. To find out the relationship between challenges facing the orphaned learners and the new family set up of learners in public primary schools in Winam division of Kisumu County, Kenya

\section{Hypothesis of the Study}

H01: The type of new family set up has no significant influence on the challenges faced by the orphaned learners. 


\section{Conceptual Framework}

The Conceptual framework shows the variables that influence the Academic achievement of Orphaned Learners within a type of family set up after demise of the parents. The variables are denoted as independent variable (IV) being the Type of family set and the dependent variable (DV) the good academic performance of the orphaned learners. The IV has constructs in terms of coping strategies that the orphaned learners use to excel in the academics despite of their vulnerable state of orphan hood. See fig.1

Figure 1. Coping Strategies influencing Good Academic Achievement of Orphaned Learners Independent Variables: Dependent Variable: Type of Family

\begin{tabular}{|l|l|l|}
\hline Type of \\
- $\begin{array}{l}\text { Suardian } \\
\text { Support of } \\
\text { Host Family } \\
\text { Dislike about } \\
\text { - } \frac{\text { Host Families }}{\text { Nhallenges in }} \\
\text { New Families }\end{array} \longrightarrow$ Self Efficacy $\longrightarrow$ Good Academic Performance \\
$\longrightarrow$
\end{tabular}

\section{Study Area}

\section{RESEARCH DESIGN AND METHODOLOGY}

The study was carried out in Winam Division in Kisumu County, Kenya. The County shares boarders with Nyando to the East, and Rachuonyo to the south, Siaya to the North and Kakamega to the west and boarded by Lake Victoria through way to neighbouring Republic of Uganda and Tanzania. It occupies an area of 559.2 square $\mathrm{km}$. It has a total population of 473,649 with a 2.1 percent population growth rate [15]. Being a boarder county and coupled with the cultural practices of the indigenous people, the region has suffered high death rates due to HIV/AIDS related causes aggrieved with cultural practices.

The division has two administrative divisions namely Winam Division and Kadibo Division. Kadibo Division performs poorly every year whereas Winam performs excellent yearly in Kenya Certificate of Primary Education (KCPE) yet has a large number of orphaned learners hence the need to use this division for the study.

\section{Research Design}

Descriptive survey design was used because of the descriptive data that was collected from a vast sample. Both qualitative and quantitative approach was used in the study. This mixed approach was necessary as the data collected comprised of both qualitative and descriptive quantitative data in terms of the type of the guardian in the family set up, the support from the family and the dislikes about the family adopted into.

\section{Sample Size and Sampling Techniques}

The study area had 43 public mixed day primary schools with 3042 orphaned learners in upper primary school, 43 head teachers and 516 teachers in mixed public primary schools in Winam Division. Only orphaned learners who had completed one year and above in the selected schools were included in the study to enable the researcher trace past academic records and assess their performance in different exams which they had done. 
The sample size therefore consisted of 234 orphaned boys and girls out of 3042, 39 teachers out of 516, and 13 head teachers out of 43 schools were selected from the public primary schools. Simple random sampling technique was used to select 13 schools from the 43 public primary schools in Winam Division. A simple purposive sampling technique was used to select 3 orphaned boys and 3 orphaned girls from Std 6, 7 and 8 in the 13 selected schools. Simple random sampling technique was used to select 3 teachers each teaching upper primary from the selected schools mixed public primary schools in Winam division. The sampling techniques were suitable for both the nature of the collected data (qualitative and quantitative) and the descriptive survey design used.

\section{Data Collection Instruments}

Data was collected by questionnaires, interview schedule and document analysis. The self developed instruments were validated by the experts from Moi University, school of education department of Curriculum Instruction and Education Media and the supervisor of this research. Both face and content validity of the instruments was established and appropriate adjustments made on the items that appeared weak. Reliability of the instruments was determined through pilot study in two primary schools which were not included in the study whereby the weaknesses noted were corrected to make them reliable. Interview, questionnaire and document analysis were justified based on the nature of the collected data such that the questionnaire addressed both quantitative data that included testing the hypothesis, and the interview and document analysis dealt with qualitative data plus some open ended items of the questionnaire. The sample size and the research design used also justified the instruments used. The three types of instruments collaborated the collected data; hence the strength of using mixed approach method.

Quantitative data was analyzed by use of descriptive statistics including frequency counties; percentages, means, and standard deviation to enable the researcher come up with clear counts concerning the responses. Correlation analysis technique was used to test if there was any significant relationship between new family set up of the orphaned learners and challenges faced, while ANOVA was used to test if there was any difference in challenges facing orphaned learners in the new family set up at a level of significance of $95 \%$ or alpha $=0.05$. Data from interviews were organized into themes and sub- themes as they emerged based on the objectives.

\section{RESULTS AND DISCUSSIONS \\ Types of Family Hosting Orphaned Learners and Coping Strategies in Academic Achievement Type of Guardian}

The orphaned learners were asked the type of family set up they live with. The learners' responses were illustrated in Figure 1.1

The Figure 1.1 shows the guardians of orphaned learners in the selected primary schools in Winam Division, Kisumu County Kenya. The data collected indicated that most orphaned learners live with their elder siblings who were either employed or engaged in other income generating activities. It was established that most orphans representing $44.06 \%$ lived with their older siblings, 38.90\% lived with their grandmothers and $11.39 \%$ lived with their aunts. Only $2.40 \%$ and $3.35 \%$ were living with their uncles and in various orphanages respectively. This implies that the relatives from either of the parents' family who ought to be the custodian of these orphaned learners could be having their own family challenges like severe economic 
problems. This could be the case since some close family members are already taking care of other orphaned learners due to the AIDS pandemic or nursing the HIV/AIDS illing family member. The relatives could also be willing to take these orphans but they prefer them brought up in their communities and home environments.

Figure 1.1. Response of Pupils on Type of Guardian

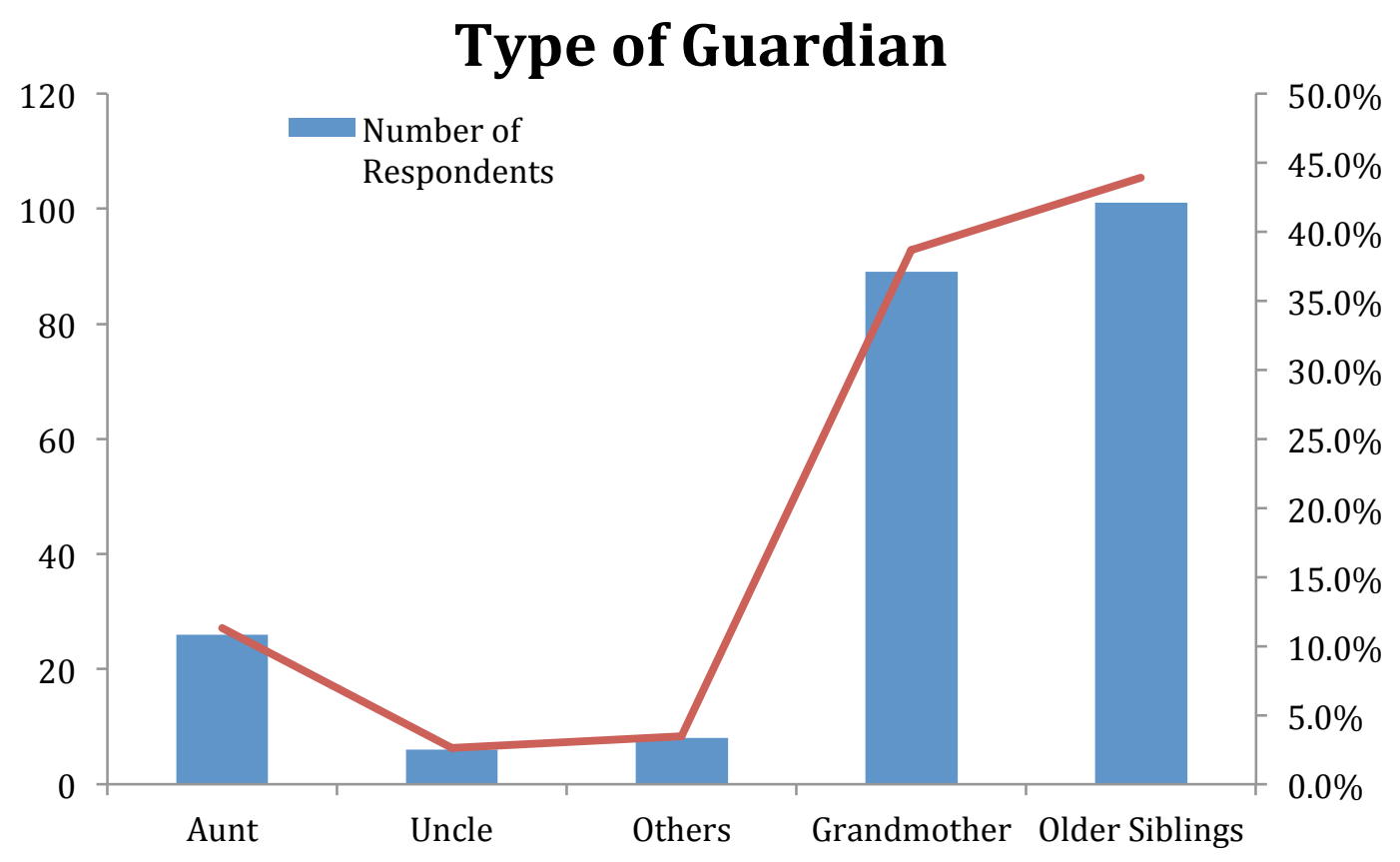

The caregivers especially the older siblings seemed to be responsible and encouraged their sisters and brothers on educational matters thus enabling them to perform well in school. This was revealed by the pupils in their open ended questions when they indicated that their elder siblings constantly told them to work hard so that they come out in future from problems related to economic constraints, HIV/AIDS infections, and related vulnerable states. This finding concurs with [16] who revealed in their study that grandparents and older orphans were forced to take the role of caregivers themselves since other relatives were also facing economic constraints.

Further studies [17] indicated that children, who lived with their brothers and sisters as guardians, pursue their education in a successful manner despite the absence of guidance and support of an adult. Whereas other orphaned learners live with their grandparents who might be unable to provide for their needs adequately, although some grandparents receive financial support from their employed children. These findings disagree with the findings by other researchers [18] who discovered that most orphans stayed with their grandparents and achieved better in their academics compared to other orphans living with other type of guardians. United States unlike Kenya, orphaned children are normally taken care by state [19]. This enables the orphans to continue with their education successfully and attain their set goals unlike in most developing countries.

\section{Orphaned Learners' View on Support Provided by the Guardians}

The study sought to establish the nature of support offered by guardians to the orphaned learner. Table 1 presents the response of the orphaned learners. According to the table majority $71.84 \%$ of orphaned learners who live with older siblings agreed that they were cared 
for by their guardians while only $5.83 \%$ were not cared for by their guardians but attention was given on their academic progress. Those who stayed with their aunts (89.58\%) admitted that their guardians were caring and were receiving almost equal treatment as other children $(88.83 \%)$ of those who were staying with their grandmothers were also cared for even though the guardians were not able to meet all their basic needs and school requirements.

These could be the reasons why they were able to perform well in their academics. This implies that the warm and nurturing environment gives the orphaned learners confidence to work hard in school. Some (10.42\%) of the orphans who were staying with their aunts also agreed that their guardians monitor their progress in school and $(23.33 \%)$ of those who were staying with older siblings were visited in schools and that their guardians monitor their progress in school. This could also motivate them to work harder in their academics.

\begin{tabular}{|c|c|c|c|c|c|c|c|c|}
\hline \multirow[t]{2}{*}{ Guardian } & \multicolumn{2}{|c|}{ Caring } & \multicolumn{2}{|c|}{ Not Caring } & \multicolumn{2}{|c|}{ Monitor } & \multicolumn{2}{|c|}{ My Progress } \\
\hline & Freq & $\%$ & Freq & $\%$ & Freq & $\%$ & Freq & $\%$ \\
\hline Aunt & 43 & 89.58 & 0 & 0 & 5 & 10.42 & 48 & 100 \\
\hline Uncle & 4 & 100 & 0 & 0 & 0 & 0 & 4 & 100 \\
\hline Grandmother & 53 & 88.83 & 0 & 0 & 7 & 11.67 & 60 & 100 \\
\hline Older & 74 & 71.84 & 6 & 5.83 & 23 & 23.33 & 103 & 100 \\
\hline \multicolumn{9}{|l|}{ Siblings } \\
\hline Orphanage & 10 & 66.67 & 0 & 0 & 5 & 33.33 & 15 & 100 \\
\hline TOTAL & 184 & 80 & 6 & 2.61 & 40 & 17.39 & 230 & 100 \\
\hline
\end{tabular}

Majority of orphaned learners were determined such that even when their guardians did not visit them in school to monitor their progress like the uncles $(0 \%)$ as shown in the Table, still they were performing very well. Further, a few who were living in orphanages received good care (66.67\%) and their academic progress were adequately (33.33\%) monitored. This possibly enabled them to do well in their academics.

Majority of the guardians (80\%) cared for the orphaned learners but paid minimal attention $(17.39 \%)$ to their academic progress. This could be due to economic constraints where they (guardians) have to find means and ways of looking after their families and the adopted orphans and therefore may not have time on their hands for follow closely the academic progress on the orphaned.

\section{Orphaned Learners Views on Dislikes in the Host Family}

Orphaned learners were asked to indicate what they did not like in the new family set up where they lived and their responses were illustrated in Table 2.

Orphaned learners who were staying with their aunts $3(6.25 \%)$ reported that they received beatings from their guardians. $5(10.42 \%)$ were discriminated by the family members while $10(20.83 \%)$ received discouraging words from family members as illustrated in Table 2 . This is 
a challenge to these orphaned learners never the less they got the love from teachers in their schools.

\begin{tabular}{|c|c|c|c|c|c|c|c|}
\hline \multirow[t]{2}{*}{ Guardian } & \multicolumn{2}{|c|}{$\begin{array}{l}\text { Beatings by the } \\
\text { guardian }\end{array}$} & \multicolumn{2}{|c|}{$\begin{array}{l}\text { Discrimination by family } \\
\text { members }\end{array}$} & \multicolumn{2}{|c|}{$\begin{array}{l}\text { Discouraging } \\
\text { words }\end{array}$} & \multirow{2}{*}{\begin{tabular}{|c|} 
Total \\
$\%$ \\
\end{tabular}} \\
\hline & Freq & $\%$ & Freq & $\%$ & Freq & $\%$ & \\
\hline Aunt & 3 & 6.25 & 5 & 10.42 & 10 & 20.83 & 48 \\
\hline Uncle & 1 & 25 & 0 & 0 & 1 & 25 & 4 \\
\hline Grandparents & 0 & 0 & 2 & 3.33 & 5 & 8.33 & 60 \\
\hline $\begin{array}{l}\text { Older } \\
\text { Siblings }\end{array}$ & 13 & 12.62 & 8 & 7.77 & 16 & 15.53 & 103 \\
\hline Orphanages & 0 & 0 & 0 & 0 & 0 & 0 & 15 \\
\hline Total & 17 & 7.39 & 15 & 6.52 & 32 & 13.48 & 230 \\
\hline
\end{tabular}

Other studies [20] revealed that children that live with their aunts are known to have fear, shyness, anger and lack of parental love. This leaves them prone to multidimensional challenges leading to psychological trauma and stress. Different studies have revealed different challenges and problems ranging between 18\% in developed countries and 54\% in developing countries. The present study to some extent concurs with their study as the learners indicated and revealed that they were not well treated. Those who were staying with older siblings $13(12.62 \%)$ received beatings, $8(7.77 \%)$ were discriminated by the family members and $16(15.53 \%)$ didn't like the discouraging words. This is a clear indication that some of these orphaned learners are treated the same way like other children in the family set up. Since they have devised their own survival mechanisms, they are able to work hard and perform better in their academics despite those challenges.

It was interesting that orphaned learners $2(3.33 \%)$ and $5(8.33 \%)$ who were staying with their grandparents and in orphanages $(0 \%)$ were not seriously facing the same challenges as others. The grandparents were found to be treating most of these orphans with a lot of care. This could be because after losing their sons and daughters then their only hope was the orphans who were their children's images. Another study [21] conducted established that grandparents provided an environment that helped children to socialize well but found it difficult to respond to their legal, economic and basic needs.

The forgoing findings coincided with views of the Head Teachers during the Interview. The Head teachers confirmed that orphaned learner lived with their relatives and in orphanages but majority lived with their elder siblings and grandmothers. The reason could be because the number of orphans as reviewed in the literature has increased and the only option is to be under the care of their elder siblings. This was slightly different under normal circumstances where majority of orphans are cared for by their grandparents after parental death. In most cases especially in African countries, the moment a parent dies the most common caregivers are grandmothers.

Others were also found to be staying with volunteers who happen to be their neighbors. This could be as a result of the nature of the caregivers left to take care of these orphans. All the families were found to have influence on academic performance of orphaned learners. The fact that most of these orphaned learners stayed with their older siblings who could be advising 
them on the importance of education could also contribute to their good performance. Others orphans who stayed with other relatives like uncles and aunts could find the family members who are geared towards better achievement in their education and enthusiastic enabling them to work hard.

\section{The Influence of the Type of Family set up on Challenges faced by Orphaned Learner}

The null hypothesis on: H01. The type of the new family set up has no significant influence on the challenges faced by orphaned learners

The testing of the hypothesis was computed by use of ANOVA. Table 3 indicates the analysis of variance.

Table 3. Relationship between Family set up and Challenges facing Orphaned Learners

\begin{tabular}{|l|l|r|l|l|l|}
\hline Variance & Sum of Square & Df & Mean of Square & F & Significance \\
\hline Regression & 90647.396 & 4 & 22661.849 & 222.710 & .000 \\
\hline Residual & 19740.47 & 226 & 101.755 & & \\
\hline Total & 110387.866 & 230 & & & \\
\hline
\end{tabular}

According to the table 3 the significance of the test is 0.000 meaning is less than 0.05 therefore the significance level of 5\% rejects the null hypothesis HO1 - The type of new family set up has no significance on challenges faced by the orphaned learners, instead is concluded that family set up had influence on the challenges faced by the orphaned learners in public primary schools in Winam division, Kisumu County Kenya.

\section{CONCLUSION}

The study concluded that the reasons for orphaned learners' good academic performance were both external and internal forces. They set targets and work towards the attainments of the targets as most of them were enthusiastic towards education. They are also able to defy all the odds and challenges facing them although different family set up have varied challenges hence they could still excel in their academics because of being highly efficacious.

\section{RECOMMENDATIONS}

Based on the findings and conclusions, the study made the following recommendations:

i. Grandparents who are not assisted by the government and are left with orphans under their care should be supported financially by the government to enable them meet some of basic needs of the orphaned learners in public primary schools in Winam division, Kisumu County.

ii. Ministry of Education, Non Governmental Organizations (NGOs) and other stake holders who are responsible for educational planning should allocate funds under Free Primary Education (FPE) to address the plight of orphaned learners who are in dire need all over the country. This can be addressed by introducing a vote head to assist orphaned learners in public primary schools.

iii. The orphaned learner at best should be encouraged to live with the closest relative like the grandparent and the older siblings to benefit from good loving and caring environment that support their academic performance in KCPE.

\section{References}

UNICEF., Childhood under threat: The state of the world children 2005

UNICEF, U.N., A World Fit for Children. Millennium Development Goals, Special Session on Children Document, the Convention on the Rights of the Child. New York; United Nations Children's Fund, 2006 
Evans, D. \& Miguel, E., Orphans and Schooling in Africa: A longitudinal analysis” Demography, 2007 44(1) pp. 3557

Meier., the Impact of Public Management and Educational Performance in Children.2003

UNICEF., Monitoring the Situation of Orphaned Children and Women, 2009

Medical Research Council of S.A. AIDS Bulletin, June 2004. Vol 13.2

UNICEF., Monitoring the Situation of Orphaned Children and Women, 2009

World Education Report. Rights to Education: Towards Education for All throughout life. Paris, UNESCO Publishing, 2000

World Education Report. Rights to Education: Towards Education for All throughout life. Paris, UNESCO Publishing, 2000

USAID., Problems with Orphans.www.unicef.org/uniceforchildren. http://www.children.org/education-out of school

http://mojuproject.com/about/orphans, 2006

UNAIDS, UNICEF. Children the Brink. Washington DC: TVT Association, 2004

Kisumu East District., Primary Schools Establishment, 2011

Meier., the Impact of Public Management and Educational Performance in Children.2003

Kisumu East District., KCPE Examination Analysis, 2011.

Republic of Kenya., Kenya Population and Housing Census, 2009

Subbarob \& Coury D., Reaching out to Africa's Orphans. Framework for Public Action: Washington D.C. 2004

Case, A., Paxson, C. \& Ableidinger,J. Orphans in Africa, Parental Death, Poverty and School Envirolment. Coggon. Planning Research. London: Oxford University, 1997

UNICEF., Monitoring the Situation of Orphaned Children and Women, 2009

Murigu, A. H. Barriers Facing Orphans and Vulnerable Children in Accessing Education in Kenya. The InterReligious Council of Kenya, 2006

Ardington, C. Orphans hood and Schooling in South Africa: Trends in the Vulnerability of Orphans. University of Cape Town. SALDRU Working paper no.16, 2008

Subbarob \& Coury D., Reaching out to Africa's Orphans. Framework for Public Action: Washington D.C. 2004 